Article

\title{
Investigating the Negative Effects of Emojis in Facebook Sponsored Ads for Establishing Sustainable Marketing in Social Media
}

\author{
Jungwoo Lee ${ }^{1}\left(\mathbb{D}\right.$, Cheong Kim ${ }^{1,2} \mathbb{D}$ and Kun Chang Lee ${ }^{1,3, * \mathbb{D}}$ \\ 1 SKK Business School, Sungkyunkwan University, Seoul 03063, Korea; ljw.bread@gmail.com (J.L.); \\ saga@g.skku.edu (C.K.) \\ 2 Predictive Analytics and Data Science, Economics Department, Airports Council International (ACI) World, \\ Montreal, QC H4Z 1G8, Canada \\ 3 Samsung Advanced Institute for Health Sciences \& Technology (SAIHST), Sungkyunkwan University, \\ Seoul 06355, Korea \\ * Correspondence: kunchanglee@gmail.com
}

check for

updates

Citation: Lee, J.; Kim, C.; Lee, K.C. Investigating the Negative Effects of Emojis in Facebook Sponsored Ads for Establishing Sustainable

Marketing in Social Media.

Sustainability 2021, 13, 4864.

https://doi.org/10.3390/su13094864

Academic Editors:

María-Ángeles Revilla-Camacho,

Dolores Garzón and Carlos

J. Rodríguez-Rad

Received: 21 March 2021

Accepted: 22 April 2021

Published: 26 April 2021

Publisher's Note: MDPI stays neutral with regard to jurisdictional claims in published maps and institutional affiliations.

Copyright: (C) 2021 by the authors. Licensee MDPI, Basel, Switzerland. This article is an open access article distributed under the terms and conditions of the Creative Commons Attribution (CC BY) license (https:/ / creativecommons.org/licenses/by/ $4.0 /)$.

\begin{abstract}
Emojis are prevalent in modern social media advertising. Despite this fact, little research can be found on its effects on consumer purchase intentions. This study seeks to examine purchase intentions in the context of Sponsored Ads on Facebook News Feeds, their perceived intrusiveness, and how the added factor of emoji presence can further affect consumer perception in order to suggest a pathway for establishing sustainable marketing strategies. We investigated the effect of emojis on consumers and then the extent to which ad personalization can attenuate intrusiveness to the point of influencing purchase intentions. In the empirical investigations (an online study) conducted, the study revealed several interesting findings. First, the emoji presence in Sponsored Ads on the News Feed did not prompt the users' perceived intrusiveness. Second, the emoji use led to decreased purchase intentions. Third, the perceived intrusiveness did not mediate the relationship between emoji presence (vs. absence) and purchase intentions. Lastly, the emoji presence decreased perceived intrusiveness and also increased purchase intentions when consumers perceived ads to be less personalized. The findings of this research provide both theoretical and managerial implications of the effects of emojis, and the reasons as to why their usage affects the desired ad goals when used in Sponsored Ads on Facebook from the perspective of sustainable marketing.
\end{abstract}

Keywords: emoji; intrusiveness; purchase intentions; personalization; sustainable marketing; social media

\section{Introduction}

For marketing practitioners, finding an appropriate pathway to sustainable marketing strategy is always a big concern. Thus, they mobilize everything they can when they conduct new marketing campaigns and events to secure a critical mass of sustainable marketing. Considering sustainable marketing in terms of marketing communication includes employing various features in the content that satisfy consumer needs; attracting consumers' attention by inserting unique elements that make marketing content stand out is one of the ways that the practitioners can try to achieve the overarching philosophy of sustainable marketing [1,2].

In this regard, emojis could be one of the simple but effective approaches. Emojis could be defined as a single picture used as a character of text [3], made as a creative and fun method to provide additional context and relay emotion [4]. It is a form of textual paralanguage in computer-mediated communication, defined as "written manifestations of nonverbal audible, tactile, and visual elements that supplement or replace written language and that can be expressed through words, symbols, images, punctuation, demarcations, or any combination of these elements," [5] (p. 1). First introduced in the late 1990s by the 
biggest mobile phone operator in Japan, NTT DoCoMo, it became even more popular when Apple added this feature in launching the first iPhone in 2007, specifically for Japanese consumers. By 2011, the emoji was starting to be used in iPhones all around the world, and the word itself had become a household name. In 2015, The Oxford English Dictionary announced the Face with Tears of Joy emoji (-2) as the word of the year. By March 2019, there were already 3019 emojis available in Unicode, and on Facebook, nearly five billion of the messages being sent daily contained emojis [6].

Much like visual cues, such as facial expressions and body language, are dominant in face-to-face communication, non-verbal cues have also become important in ComputerMediated Communication (CMC). An emoji takes the place of visual cues where faceto-face communication is not possible. As a result, all forms of online communication now contain emojis, including the aspect of sustainable marketing communication strategy. From traditional advertising methods, such as print ads and billboards, to the more modern website banner ads and electronic direct marketing, emojis have been incorporated for a more light-hearted approach and to convey emotions and feelings where text-heavy ads cannot. To generate hype, some famous brands, such as Sony, Chevron and Coca-Cola, have even created customized emojis [7].

This paper focuses on the impact of emojis on consumers' purchase intention in the context of Sponsored Ads on Facebook from the perspective of sustainable marketing. Advertisers have started using the social media platform, Facebook, to reach out to their target audience because it is where consumers spend the majority of their time. Ads on Facebook appear on people's News Feeds as part of the usual content. A feature introduced by the social media giant in 2006, the News Feed is the landing page of every user's Facebook page. The social media platforms aim to create a community where users add friends and like news or entertainment pages to receive the latest updates. The News Feed functions as a live update section, which is a highly optimized place for achieving a fundamental basis of sustainable marketing; it is a scrollable page that constantly updates to feature recent activity happening in a user's community, such as when friends interact with posts, news providers publish articles, and so on [4].

As this is where users spend most of their time paying attention to the ongoings within their community [6,8], marketers can use this section to put up advertisements that they have personalized with tools, such as user-supplied data findings and data-tracking technology [9]. Emojis can be introduced into these ads to draw attention and create a more approachable perception from the perspective of sustainable marketing strategies. The ads will turn up on News Feeds labeled as "Sponsored Ads" [6]. Due to regulations set by the Federal Trade Commission (FTC) in the United States surrounding advertising on social media, wherein marketers must explicitly disclose that it is, in fact, an advertisement, ads must be labeled accordingly so that consumers will be made aware of when a message has persuasive intent [10].

It is worth noting that the presence of Sponsored Ads alone can already be deemed intrusive by users, which would severely harm the fundamental goal of sustainable marketing concepts. This is particularly because personalized ads are a result of data put together from the user's profile, cookies, and browsing history to gauge user preference and desired products. For example, a user who searches for "Skincare" through a search engine such as Google would soon notice Sponsored Ads for various skincare brands on their News Feeds.

Despite the prevalence of emojis in marketing communications, there is limited empirical research about the influence of emoji usage in ads on purchase intention from the perspective of sustainable marketing. A potential issue is that some users may consider the ad jarring to their ongoing cognitive process [11]. Users browse through their News Feed with a mindset in place, and the sudden appearance of an ad would be an interruption. Moreover, the usage of emojis in those ads could potentially cause negative emotions for the users, in which the ad appears as a regular post until users notice the label "Sponsored Ad". Although emojis lend an air of lightheartedness to the marketing content and fits in 
with user-created posts on the News Feed, some users could potentially find the confusion frustrating. Empirical research is limited because it is difficult to gauge consumer perception. The perception of emoji use in marketing communication is subjective since different emojis resonate with different users.

In light of this observation for sustainable marketing, our research thus aims to (1) investigate the impact of emoji use in Sponsored Ads on consumers' purchase intentions and gauge its perceived intrusiveness, (2) examine whether the emoji may decrease purchase intentions by testing whether intrusiveness mediates the effect of emojis on purchase intentions, and (3) test whether emojis lead to perceived intrusiveness and decrease purchase intentions when Facebooks users perceive the personalized ad.

\section{Theoretical Background and Hypotheses Development}

\subsection{Emoji in Marketing Communication}

In social situations, facial expressions play a pivotal role in relaying intention, and have the power to set the overall tone of the interaction [12]. In computer-mediated communication, the emoji plays that role as a graphic representation of emotion. Emojis, such as the smiling emoji, have come to communicate warmth $[13,14]$. Additionally, research has shown that emojis are used by consumers to deliver both emotions and intentions, so it is also perceived as a relational tool [15-17].

Emojis can reduce confusion, deliver sense and feeling, and explain purpose [18,19]. A shape of paralinguistic communication, even a sole emoji can be valuable in terms of serving as a visual guide and carries dense information with playfulness simultaneously [20,21]. Emojis can be contemplated as metaphorical portraits, which induce persuasion [22,23].

McShane, Pancer, Poole and Deng [15] state that emojis have an intrinsic spirit, which stimulates wonder about the content, accordingly adding to the interactional importance. Researchers focused on online communications between service providers and customers. Li, Chan and Kim [14] found that customer service representatives who used emoticons (i.e., a subset of emojis, using keyboard symbols to depict facial expressions) when responding to online customers were considered more approachable. Therefore, customers who had comments and questions were more open during a conversation with them.

Considering these notions with the sustainable marketing concepts, it can be assumed that emojis strongly affect user perception in various aspects [7]. Therefore, the use of emojis in advertising could influence purchase intentions. Research by Das et al. [24] found that consumers experienced a more positive effect when emojis were present, which resulted in higher purchase intentions. An ad containing an emoji would be perceived as more relatable, hence capturing user attention for much longer than an ad without emojis.

Facebook users are visually driven, consuming large amounts of content daily through their News Feeds. Additionally, because the frequency of emoji usage has become boosted dramatically in every online-based communication method, people nowadays are familiar with using and seeing emojis across the internet in which marketers can optimize their sustainable marketing strategies. These days, social media content without emojis can even be seen as unwelcoming. Firms' marketing communication messages containing emojis can also be more appealing and convincing $[19,23,25]$, in contrast with just text and emoticons [26]. As a result, the use of emojis in marketing messages is effective in improving the chances of persuasion [27].

\subsection{The Impact of Emoji on Perceived Intrusiveness}

The placement of Sponsored Ads on a user's Facebook News Feed can result in perceived intrusiveness. Users have grown accustomed to their News Feeds, using it as an activity log of what their friends are doing. When marketers pay for ads to reach and interact with large audiences, Sponsored Ads appear among the usual News Feed content while users are interacting with their friends [4]. This can be perceived as an intrusion on their personal space [4]. 
Sponsored Ads on Facebook News Feeds are tailored specifically to the users seeing them, deriving data from their online behavior: product searches, product information sharing, location, etc. Therefore, not only is the actual presence of the ad intruding on their personal space, but its perceived intrusiveness is also increased as users realize that the message being conveyed is personalized, targeting their searches and the articles that they interacted with. As Facebook increases the display of Sponsored Ads in News Feeds, concerns about privacy issues increase, too [9]. As a result, social media users' perceptions of intrusion from ads rise, obstructing their cognition, which marks the campaign's repudiation and failure [11].

Additionally, because marketers have introduced emojis into their marketing communications in an attempt to persuade consumers emotionally for achieving sustainable marketing goals, it results in users' recognition of intrusiveness, "a psychological reaction when consumers believe an ad has interrupted their ongoing cognitive process" [11] (p. 39). Due to the persuasive characteristics of emojis [23], their presence in advertising messages amplifies this. Once users recognize the ad as intrusive, it becomes a steep decline as they begin to actively interpret the persuasive techniques and messages used in the ad [28], paying close attention to the message to form counterarguments against the ad claims [29].

This occurrence can be explained with the psychological reactance theory, which explains that individuals negatively react when they believe that their freedom of behavior is vulnerable to threats or limitations [30]. The persuasive attributes of the personalized ad and emojis in it increase this belief because marketing messaging typically asks consumers to behave in a specific way. Consumers desire behavioral freedom and individuality in their purchase intentions, so they reject the idea of being influenced. As a result, this reactance spurs them to resist the message to restore their behavioral freedom [31]. While this reactance can happen with any Sponsored Ad, we hypothesize that messages using emojis will only serve to amplify the psychological reactance theory, as emojis will be seen as a further attempt at persuasion.

The emotions as social information theory [32] states that an individual's social influence can be affected by their emotional expressions. Expressions are influential in affecting the situation as a whole, particularly when relaying unwanted emotions that can be perceived as inappropriate. They can affect the other individual's emotions negatively, harming the relationship and thus their impression of the expresser. This translates to emoji use in sponsored advertising communications, wherein the usage of emojis can result in a misunderstanding of the intended message, harming the purchase intention. This negative effect then results in consumers perceiving the ad as a whole to be intrusive. They would then reject the message, triggering their cognitive resistance by consciously throwing up walls [33]. We posit that Sponsored Ad messages using emojis will amplify the psychological reactance theory, as not only is it intrusive to consumers' personal space, but the emoji is seen as a blatant attempt at persuasion. Specifically, we expect the following:

Hypothesis 1 (H1). Emojis in sponsored advertisements in Facebook News Feeds will lead to higher intrusiveness.

\subsection{Emoji and Purchase Intention}

When research focused on how service providers are viewed during online communications when they use emojis versus when they do not, Li, Chan and Kim [14] found that while service employees who used emoticons were seen as warmer, they were perceived as less competent compared to those who did not. This perception plays a large role in influencing subsequent purchasing behavior. Customers were more willing to complete the purchase when they believed the service provider to be competent and, therefore, trustworthy; thus, it can take a step closer to the notion of sustainable marketing. In advertising communications, however, the effects were reversed. Das, Wiener and Kareklas [24] proved that when advertisements contained emojis, the positive effects were increased, resulting 
in more favorable purchase intentions. In comparison, advertisements without emojis had lower purchase intentions.

Studies showed that the usage of emojis in a formal setting (i.e., work environment) is considered inappropriate because it harms perceptions of the writer's maturity and verbal ability [34]. Due to the playful nature of emojis, it is perceived as intrusive and unprofessional, hence frowned upon in the workplace. Li, Chan and Kim [14] found that relationships are viewed as exchange-based in work-related contexts, so the use of emoticons is harmful because it leads the interaction toward a more casual basis. The exchange-based qualities of the communication would be harmed, putting the outcome of the exchange at risk. While emojis may help the writer convey warmth and friendliness in an attempt to improve the working relationship, often in a formal setting it results in the perception that the writer is incompetent and unprofessional.

The above leads us to this finding on the use of emojis by service employees versus advertising communications: as customer service is exchange-based, emoji presence in the communication harms the perception that the customer has toward the employee. On the contrary, advertising communication begins as a one-way relationship that is on a more casual basis; thus, the use of emojis can produce positive results.

Empirical research has yet to establish whether concerns of intrusiveness can be a deterrent for marketers who wish to advertise on social media. Advertisements that resulted in lower purchase intentions had several possible factors, such as personalization, emoji use, and content. Consumer behavior is subjective; hence, either or all factors could have played a role in the negative results. Based on the preliminary findings on the negative effects that perceived intrusiveness can have toward purchase intentions [35], privacy concerns are a factor in affecting users' feelings toward Sponsored Ads on Facebook and consequently, negatively affect their intention to purchase the advertised product [36]. With this finding in mind, we reason that when emoji use in these Sponsored Ads is mediated by the effect of intrusiveness, it will further affect consumer purchase intentions. The following hypotheses are proposed to validate the reasoning from the perspective of sustainable marketing.

Hypothesis 2 (H2). Emojis in sponsored advertisements in Facebook News Feeds will lead to lower purchase intentions.

Hypothesis 3 (H3). Increased intrusiveness will mediate the effect of emojis in sponsored advertisements on decreased purchase intentions on Facebook.

\subsection{Moderating Effects of Personalization}

Personalization can be beneficial but also risky from the perspective of social media users. Sponsored Ads are personalized with user data: product searches, brand interactions, location, demographics, and more. This is done to influence purchase intention by targeting the right audiences, i.e., sportswear advertisements targeted toward users who liked and shared an exercise video, new apartments advertised to users who searched for places to rent, and so on. In this regard, personalization may be used as a significant factor in establishing sustainable marketing strategies. Regardless of targeting the personalized content's adequacy, highly personalized advertising initiates the receivers' sense of losing control [37], generating the idea that they are being observed and interfered with. The use of consumers' personal information intensifies the ad's intrusiveness, interrupting consumers' cognitive processing and risking goal pursuit [11]. Moreover, Sponsored Ads are introduced in the News Feed, a platform that Facebook users perceive as a safe space. Personalized ads show without notice, triggering negative responses when consumers begin to consider that their privacy is in danger [38].

Nearly every Sponsored Ad on Facebook utilizes emojis as a persuasion tactic. It is an integral part of brand communication, lending familiarity and a touch of playfulness to ad copy. Different audiences respond differently to emoji use; hence, advertising messages tailor them to appeal to their targeted audience. Younger audiences, for example, 
have made an art of emoji use, communicating a whole sentence with the help of just three emojis (e.g., 10 could mean "should I eat pasta or pizza?"). Once consumers notice this happening, the ad is perceived as intrusive and induces loss of control. As a result, personalized advertising on the Facebook News Feed can have a negative effect on users [39] (the psychological reactance theory). Their negative reaction then blocks them from receiving the ad intent [40].

$\mathrm{Xu}$ [41] points out, though, that the intrusiveness of advertising can occasionally be offset by its personalization. Youn and Shin [42] empirically tested that the perceived intrusiveness of Sponsored Ads to Facebook users was lessened when they were determined to be beneficial. When personalized ads are well-made and well-placed, the information within is relevant and useful to the targeted consumer, thus increasing its value. By utilizing social media platforms, marketers have more access to user-supplied data findings and data-tracking technology than ever before, allowing the advertisement to be customized with persuasive messages and content based on user preferences and online activity [43]. As marketing is aimed at convincing and satisfying consumers to improve purchase intentions, researchers have stressed that personalization is important to ensure accuracy in targeting and improve goal pursuit [44]. Once customers are satisfied with the service, this even results in a privacy paradox in which consumers continue revealing personal information in their pursuit of purchase intention, despite their previous concerns of privacy $[42,45,46]$. Tam and Ho (2006) [47] stated that when personalized ads are appropriately exposed, they positively affect consumers' intentions.

Although personalized advertising can increase the level of intrusion and privacy risk perception, these elements are diminished when the target consumers determine that the message is valuable $[42,46,47]$. Sponsored Ads, which are well-personalized with an appropriate subject, can be contributory in mitigating intrusiveness perceptions. Once all marketing communication factors are in synergy, the Sponsored Ad will positively affect consumers, enhance purchase intentions, and achieve the goal of sustainable marketing. Therefore, we expect the following:

Hypothesis 4 (H4). Emojis in sponsored advertisements in Facebook News Feeds will lead to increased perceived intrusiveness. However, these effects will be attenuated by the personalization of the ad.

Hypothesis 5 (H5). Emojis in sponsored advertisements in Facebook News Feeds will mediate their effect on purchase intentions. However, these effects will be attenuated by the personalization of the ad.

\section{Research Model}

Figure 1 illustrates the conceptual model guiding our research hypotheses derived on the hypotheses from the perspective of establishing sustainable marketing strategies.

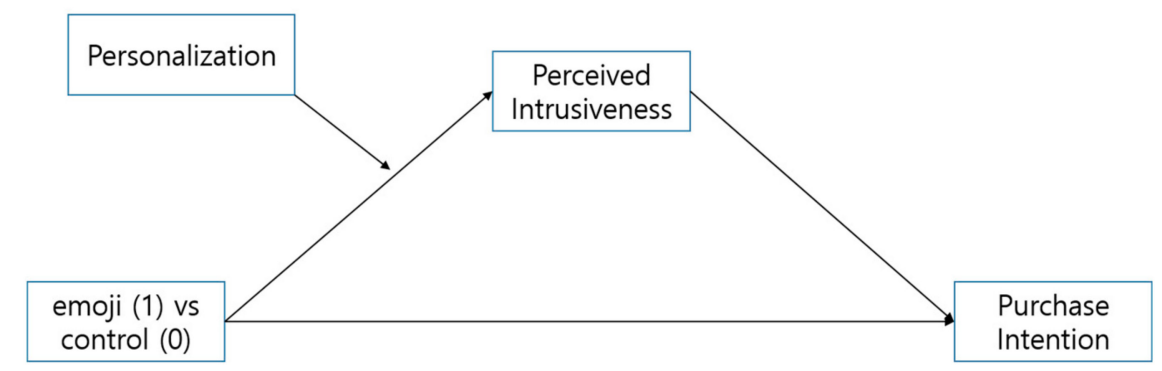

Figure 1. Research model. 


\section{Method}

\subsection{Design and Participants}

This research had a 2-cell (emoji: present vs. absent) between-subjects design. Four hundred Korean residents participated in the research survey (50\% female, 50\% male, age $=33.7$ years) $($ Table 1$)$. All participants are active users who have accounts on Facebook. They received minimal compensation for their participation.

Table 1. Demographic characteristics $(n=400)$.

\begin{tabular}{|c|c|c|}
\hline \multicolumn{2}{|c|}{ Variables } & \multirow{2}{*}{$\begin{array}{c}\% \\
5.0\end{array}$} \\
\hline \multirow{5}{*}{ Age } & 19 or younger & \\
\hline & $20-30$ & 35.0 \\
\hline & $30-40$ & 35.0 \\
\hline & $41-50$ & 20.0 \\
\hline & 50 or older & 5.0 \\
\hline \multirow{2}{*}{ Gender } & Female & 50.0 \\
\hline & Male & 50.0 \\
\hline \multirow{7}{*}{ Occupation } & Sales & 6.5 \\
\hline & Office Job & 56.0 \\
\hline & Professional & 8.3 \\
\hline & Self-employed & 3.8 \\
\hline & Unemployed & 3.5 \\
\hline & Student & 16.3 \\
\hline & Etc. & 5.8 \\
\hline \multirow{5}{*}{ Income } & Less than USD 24,999 & 35.5 \\
\hline & USD 25,000-44,999 & 33.8 \\
\hline & USD 45,000-71,999 & 23.3 \\
\hline & USD 72,000-89,000 & 6.0 \\
\hline & More than USD 90,000 & 1.5 \\
\hline \multirow{4}{*}{ Education } & High school graduate and below & 10.2 \\
\hline & Bachelor's degree & 70.8 \\
\hline & Master's degree & 15.0 \\
\hline & Doctoral degree & 4.0 \\
\hline \multirow{4}{*}{ Period of using Facebook } & Less than 6 months & 0.5 \\
\hline & 6 months to 1 year & 2.8 \\
\hline & 1 year to 2 years & 5.8 \\
\hline & More than 2 years & 91.0 \\
\hline \multirow{5}{*}{ Time of using Facebook per day } & Less than $1 \mathrm{~h}$ & 38.0 \\
\hline & $1-3 \mathrm{~h}$ & 48.0 \\
\hline & $3-5 \mathrm{~h}$ & 11.0 \\
\hline & $5-7 \mathrm{~h}$ & 2.3 \\
\hline & More than $7 \mathrm{~h}$ & 0.8 \\
\hline
\end{tabular}

\subsection{Procedures}

The data from this study were obtained by enlisting a professional surveyor holding a sizable panel of participants from 13 to 19 January 2021. When participants accessed the designated website, they were informed that the survey was aimed at testing the effectiveness of the camera advertising that they would see on their News Feed. Prior to the full-fledged survey, the participants were asked to open their Facebook accounts and write down the Sponsored Ads that they saw on their News Feed, with a reminder that the study is targeted at Facebook Sponsored Ads. The ad used in this study was a digital camera ad [24,48]. Emojis were included in only one of the ads. For emoji conditions, the adverting message contained emojis, and in the controlled condition, the same message was shown without emojis (see Appendix A). All messages were written in Korean, and participants were randomly exposed to the two advertisements. 


\subsection{Measures}

All measurements were adapted from existing literature (see Table 2): Purchase Intentions [24], Perceived Intrusiveness [49], and Personalization [38,42]. The measurements used 7-Likert scales with 1 being "Strongly disagree" and 7 "Strongly agree".

Table 2. Summary of measurement model statistics.

\begin{tabular}{|c|c|c|c|c|}
\hline Construct & Item & Mean & SD & Loading \\
\hline \multirow{4}{*}{$\begin{array}{c}\text { Perceived } \\
\text { Intrusiveness } \\
(\alpha=0.904)\end{array}$} & 1. This advertising I saw was obtrusive. & 3.55 & 1.545 & 0.888 \\
\hline & 2. This advertising I saw was intrusive. & 3.90 & 1.631 & 0.883 \\
\hline & 3. This advertising I saw was forced. & 3.68 & 1.531 & 0.857 \\
\hline & 4. This advertising I saw was distracting. & 3.55 & 1.545 & 0.888 \\
\hline \multirow{3}{*}{$\begin{array}{c}\text { Perceived } \\
\text { Personalization } \\
(\alpha=0.921)\end{array}$} & $\begin{array}{l}\text { 1. I believe that this personalized advertising on Facebook is } \\
\text { customized to my needs. }\end{array}$ & 3.90 & 1.631 & 0.883 \\
\hline & $\begin{array}{l}\text { 2. This Sponsored Ad on Facebook News Feed enables me to } \\
\text { know products that I am interested in. }\end{array}$ & 3.68 & 1.531 & 0.857 \\
\hline & $\begin{array}{l}\text { 3. This Sponsored Ad on Facebook News Feed makes } \\
\text { purchase recommendations that match my needs. }\end{array}$ & 3.55 & 1.545 & 0.888 \\
\hline Purchase & 1. How willing are you to buy the advertised product? & 3.90 & 1.631 & 0.883 \\
\hline Intention & 2. How inclined are you to buy the advertised product? & 3.68 & 1.531 & 0.857 \\
\hline$(\alpha=0.891)$ & 3. How likely would you be to buy the advertised product? & 3.55 & 1.545 & 0.888 \\
\hline
\end{tabular}

\subsection{Statistical Analysis}

Statistical analyses were conducted with the Statistical Package for the Social Sciences (SPSS, New York, NY, USA) 22 and the macro process version 3.5.2 (www.processmacro. org/index.html, accessed on 22 January 2021). The third, fourth, and fifth hypotheses were tested using the PROCESS macro developed by Andrew Hayes [50]. Specifically, the bootstrapping procedure, as outlined by Preacher and Hayes [51,52], was used.

\section{Results}

\subsection{Effect of Emojis on Intrusiveness and Purchase Intentions}

We first tested the effect of the presence versus absence of emojis in the advertisement on intrusiveness. There was no significant main effect of emojis on intrusiveness $\left(t(398)=0.799, p=0.372, \eta^{2} p=0.002\right)$, such that participants in the emoji present condition $(\mathrm{M}=3.131)$ did not perceive statistically significant intrusiveness compared to those in the absent emoji condition $(M=3.265)$. These results do not support Hypothesis 1 . We then examined the effect of the presence of emojis on purchase intentions and found that participants in the emoji present condition $(\mathrm{M}=3.548)$ reported lower purchase intentions than did the participants in the absent emoji condition $(\mathrm{M}=3.870 ; t(398)=4.905, p=0.027$, $\eta^{2} p=0.012$ ). These results support Hypothesis 2 .

\subsection{Mediating Effect of Intrusiveness on Purchase Intentions}

We predicted that intrusiveness would mediate the effect of the presence of emojis on purchase intentions. We used PROCESS model 4 with 10,000 bootstrap samples to test this proposition [50]. The model considered the presence versus absence of emojis as the independent variable, intrusiveness as the mediator, and purchase intentions as the dependent variable. The results showed that a direct effect, such that the presence of emojis decreased purchase intentions ( $b=-0.355,95 \%$ CI $[-0.632,-0.079])$. However, the indirect effect of emojis on purchase intentions through intrusiveness was not significant $(\mathrm{b}=0.033,95 \% \mathrm{CI}[-0.038,0.117])$. These results do not support Hypothesis 3.

\subsection{Moderating Effect of Intrusiveness}

We examined the effect of the presence of the emoji and personalization on intrusiveness by using PROCESS model 1 [50] with 10,000 bootstrap samples. Results show that the 
moderation effect of personalization was significant $(b=0.284,95 \% \mathrm{CI}[0.051,0.517])$, and there is considerable interaction between the presence of the emoji and intrusiveness in the low condition of personalization $(b=-0.621,95 \%$ CI $[-1.034,-0.2040]$, such that participants who saw the advertisement containing the emoji felt less intrusiveness (see Figure 2); hence, the presence of the emoji only decreased intrusiveness in the low personalization, supporting Hypothesis 4.

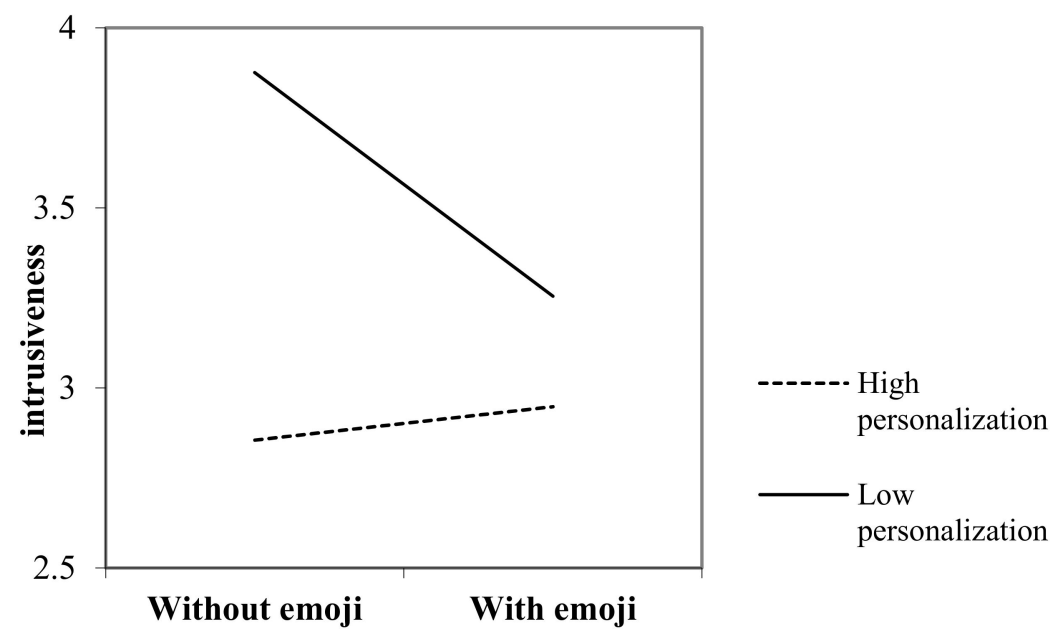

Figure 2. Moderation of the effect of emoji on intrusiveness at values of the moderator personalization.

\subsection{Moderated Mediation Effect on Purchase Intention}

To examine whether the positive effect mediates the impact of the product type by emoji interaction on purchase intentions, we used PROCESS model 7 (PROCESS v.7) [50] with 10,000 bootstrap samples. This SPSS macro uses an ordinary least squares regressionbased path analytical framework to estimate the direct and indirect effects in mediator models. We used 10,000 bootstrap samples to assess the $95 \%$ bias-corrected bootstrap confidence intervals (BCIs) for inferences regarding indirect effects and conditional effects [6].

We ran a model with emojis as the independent variable, personalization as the moderator, intrusiveness as the mediator, and purchase intention as the dependent variable. The results showed that the index of moderated mediation was significant $(b=-0.074,95 \%$ CI $[-0.159,-0.008])$. In the condition of perceived personalization, there was a significant indirect effect of emojis on purchase intentions $(b=0.168,95 \%$ CI $[0.038,0.335])$. However, since the direct effect of emojis on purchase intentions is significant $(b=-0.350,95 \% \mathrm{CI}$ $[-0.632,-0.068])$ in the model, perceived intrusiveness partially mediates the effect of emojis on purchase intentions. Therefore, there was a significant moderated mediation effect of emojis on purchase intentions, such that the presence of emojis increased the likelihood of purchase intention through decreased intrusiveness. Specifically, in the high perceived personalization, the indirect effect of perceived intrusiveness was not significant $(b=-0.019,95 \%$ CI $[-0.132,0.089])$; however, in the low perceived personalization condition, the indirect effect was significant $(b=0.168,95 \%$ CI $[0.038,0.335])$ (see Table 3 and Figure 3). These results support Hypothesis 5. 
Table 3. Moderated mediation effects of the presence of emoji and perceived personalization.

\begin{tabular}{|c|c|c|c|c|c|c|}
\hline \multirow{3}{*}{ Path } & \multirow{3}{*}{$\begin{array}{l}\text { Index of } \\
\text { Moderated } \\
\text { Mediation }\end{array}$} & \multirow{3}{*}{$\begin{array}{l}\text { 95\% Confidence } \\
\text { Interval }\end{array}$} & \multicolumn{4}{|c|}{ Conditional Indirect Effects (IEs) for Perceived Personalization } \\
\hline & & & \multicolumn{2}{|c|}{$\begin{array}{l}\text { Low Perceived } \\
\text { Personalization }\end{array}$} & \multicolumn{2}{|c|}{$\begin{array}{l}\text { High Perceived } \\
\text { Personalization }\end{array}$} \\
\hline & & & IE & $95 \%$ CI & IE & $95 \% \mathrm{CI}$ \\
\hline $\begin{array}{l}\text { Emoji } \rightarrow \text { INT }^{1} \\
\quad \rightarrow \text { PUR }^{2}\end{array}$ & -0.074 & {$[-0.159,-0.008]$} & $0.168^{3}$ & {$[0.038,0.335]$} & $-0.019^{4}$ & {$[-0.132,0.089]$} \\
\hline
\end{tabular}

Notes: the index of moderated mediation is the test of moderated (or conditional) mediation for the mediation path [50]. The CIs are the bias-corrected bootstrap $95 \%$ confidence intervals. The presence of emojis was dummy coded $(0=$ control, $1=$ emoji $) .^{1}$ Perceived Intrusiveness, ${ }^{2}$ Purchase Intention, ${ }^{3}$ the range between LLCI and ULCI includes 0 , which means the effect is not significant, ${ }^{4}$ the range between LLCI and ULCI does not include 0 , which means the effect is significant.

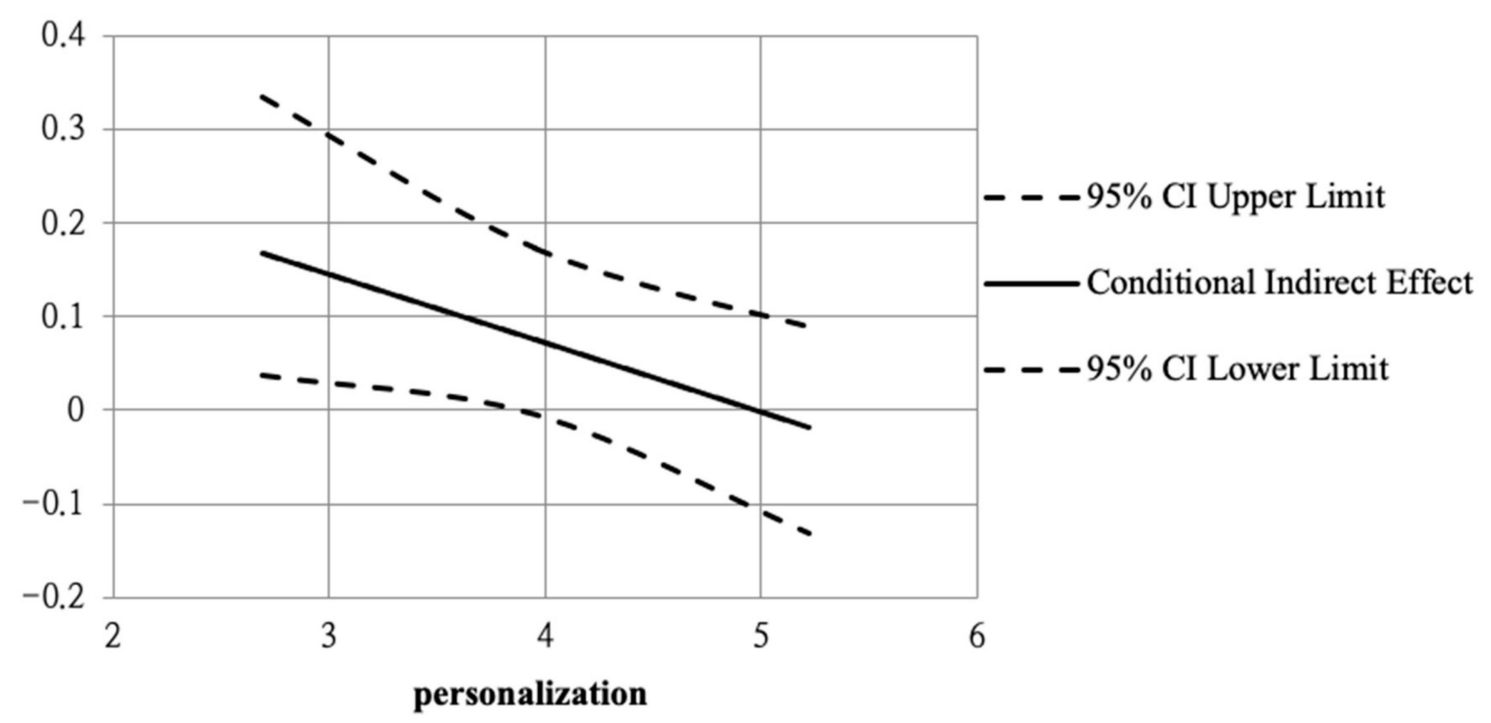

Figure 3. Effect of emojis on purchase intention at values of the moderator personalization through intrusiveness.

\section{Discussion}

Prompted by the recent influx of Sponsored Ads and the lack of empirical evidence surrounding the effects of emojis on social media marketing, this study sought to investigate how emoji presence would affect Sponsored Ad performance for accomplishing sustainable marketing whereby companies can gratify consumers, as Fuller [1] suggested. By measuring three factors, including purchase intentions, perceived intrusiveness, and personalization, we examined how emojis can affect consumer behavior. We tested how emojis lower purchase intentions by examining whether perceived intrusiveness can mediate the correlation between the two. Then, we gauged whether emojis would further affect perceived intrusiveness and decrease consumers' purchase intentions once the Facebook users perceived the ad to be personalized.

In the online survey conducted with active Facebook users, it was found that emoji presence in Sponsored Ads on the News Feed did not prompt the users' perceived intrusiveness. However, the emoji presence did result in decreased purchase intentions. Additionally, we found that perceived intrusiveness did not mediate the correlation between emoji presence (vs. absence) and purchase intentions. Finally, we gauged that emojis can decrease perceived intrusiveness and also increase purchase intentions once users perceive the ad to be personalized. Specifically, the personalization of the Sponsored Ad was effective when the perceptions of personalization were low.

As for the empirical survey, one of the more consistent findings was that the use of emojis does not increase purchase intentions but, in fact, reduces intentions to buy. However, the effects were reversed when consumers perceived the ad as less personalized. 
We can theorize that this is due to the intrusive nature of personalization. While previous research examined how consumers' purchase and behavioral intentions could be positively affected by emojis (see $[14,24,53])$, the current research revealed that emojis actually negatively affect purchase intentions when present in ads. Considering that the scene of purchasing a digital camera for consumers should not be regarded as an informal setting due to the level of involvement related to its high price characteristic, these results are in alignment with the previous literature that explored the effect of emojis in a formal setting on the perception of the workplace [14], and writers' maturity and verbal abilities [34]. Based on our research, we reveal for the first time that emojis can be harmful when used in the context of Sponsored Ads on Facebook News Feeds. In addition, we discovered an opposite effect of emojis that positively influenced consumers' purchase intentions in the research by Das, Wiener and Kareklas [24]. We presume that the difference is because of the size of the emojis in the stimuli, which were abnormally large in the study of Das, Wiener and Kareklas [24], whilst relatively reasonably sized in the stimuli of this paper. The overarching philosophy of implementing personalized Sponsored Ads on Facebook News Feeds is to articulate the products or brands rather than an emoji itself. Thus, we could argue that this research reflects more realistic examples than the previous literature.

Our findings contribute to the ever-growing literature on the emoji and its effects. We find that emojis only lead to positive effects when they are deemed appropriate for the context. At this point, we would direct attention to the bigger question behind the efficacy of emojis - not the usage of emoji itself, but directed towards the user's perception of their personal online space and the difference between friendly content and Sponsored Ads. We find that emojis elicit a positive reaction only when perceived to be appropriate within the user's personal space. That is to say, similar to Sponsored Ads, emojis may be seen as an intrusion of personal space. Counterintuitively, the less personalized they are in Sponsored Ads, the less they trigger the user's mental flags. Advertising research has even shown that consumer purchase intentions increase when they perceive the offers to be tailored to their preferences [54,55]. Thus, emojis in Sponsored Ads should be used with this awareness in mind and crafted to portray a polite but distanced personality rather than an intimate or close associate.

Given the nature of our findings, it is apparent that little can be determined regarding the general effectiveness of emojis as they are currently used in marketing communications due to their subjective nature. Research on whether marketers should use emojis and how to use them effectively in customer communications is limited [24]. Instead of relying solely on emojis, our research recommends alternate content strategies based not on personalization but other engaging content to appear less intrusive, leading to increased purchase intentions [4]. Engaging content would include items encompassing education or information (e.g., opinion pieces) or entertainment (e.g., memes). This strategy works towards the recognition of the Facebook News Feed as a user's personal space and how to go about synchronizing with the personal space as opposed to introducing elements that may be foreign to it. Marketers should keep in mind that from the perspective of sustainable marketing, users value their personal space online just as much as they do in real life, and an incursion would be an intrusion to that value [4].

Even though this study uncovered valuable implications on emojis' effects on purchase intentions when used in Sponsored Ads by examining their perceived intrusiveness and personalization, this research still has limitations. First, we used the manipulated Facebook ads on the website for the participants to effectively control other effects except emojis.

If they were real advertisements with several likes, comments, and shares included in their Facebook News Feed, the consumers' behavior could be different. Second, we used the digital camera, which is a high-involvement product, for the advertisement; however, consumer responses to emoji presence would vary depending on the product type. Lastly, the research is a Korea-based study (most participants are from Korea and use Facebook). Although emoji use in social media advertisements is prevalent in the country, 
the generalizability of the results is limited due to the sample from a small group of a specific country.

This study is an initial attempt on an empirical study of consumers' negative responses toward emoji use in Sponsored Ads on Facebook. Further research directions to be taken in the future would encompass testing emoji use in the various scopes of advertising, such as user re-promoted vs. marketer promoted. It is worth noting that there is a caveat to emoji use on Facebook Sponsored Ads, which involves user re-promoted ads shown as "My Friends Liked", and "I Liked". Since these types of content are derived from activities in the user's Facebook community, they are perceived to be less intrusive due to their known source and to add credibility. Therefore, future research on the effect of emojis in different contexts is expected to provide further insights on how and when to use emojis in marketing communications.

\section{Conclusions}

Finally, based on our studies, emojis used in advertising, in this case, in Sponsored Ads on Facebook, may ultimately lead to lesser purchase intentions, particularly for ads that are apparent in their intention to be user-personalized to users. Conversely, when ads are written in a tone of distant professionalism, hence less personalized, emojis have a more positive effect. We could theorize the effect of emojis as related to the human expressions behind them, such as a stranger trying to pull off a friendly smile (Sponsored Ads) as compared to an actual friend smiling (user-shared content). Emojis play a large role in computer-mediated communication on social media but many questions about its efficacy in social media marketing remain unanswered. We believe that our research has provided insightful directions that could inform marketers and advertisers seeking the pathway to the core of sustainable marketing.

Author Contributions: Methodology, J.L.; conceptualization, J.L. and C.K.; software, J.L. and C.K.; validation, J.L. and C.K.; investigation, J.L.; resources, K.C.L., J.L. and C.K.; data curation, J.L. and C.K.; writing—original draft preparation, J.L. and C.K.; writing—review and editing, J.L., C.K. and K.C.L.; visualization, J.L.; supervision, K.C.L.; project administration, K.C.L.; funding acquisition, K.C.L. All authors have read and agreed to the published version of the manuscript.

Funding: This paper was supported by SKKU Excellence in Research Award Research Fund, Sungkyunkwan University, 2020.

Institutional Review Board Statement: This study was conducted with the approval of Sungkyunkwan University, in compliance with the guidelines and regulations of the university institutional review board (IRB no. 2017-12-011-022) for the method.

Informed Consent Statement: Informed consent was obtained from all subjects involved in the study.

Data Availability Statement: Not applicable.

Conflicts of Interest: The authors declare no conflict of interest. 


\section{Appendix A}

\section{SNAPTEECHA SNAP TECH Inc.}

Experience the joy of TechCam's all-new digital camera Moments with your family and friends will be instantly captured and saved in SNS and your cloud . And update your Youtube status everyday. Record and share your joyous moments with TechCam .

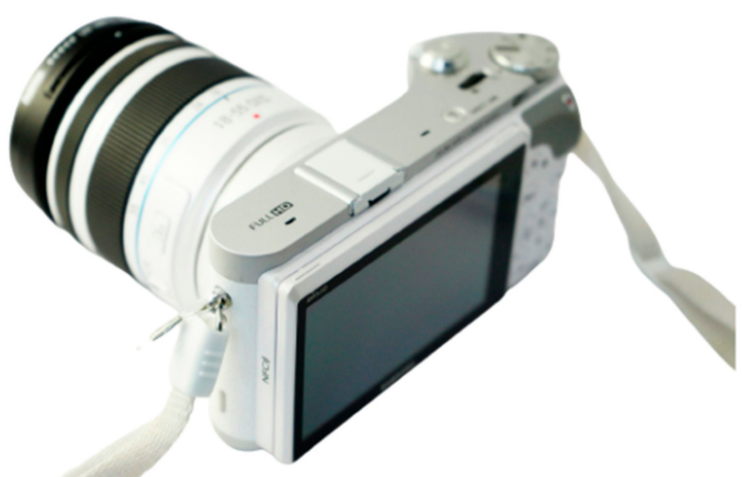

\section{TECHCAM.COM PURCHASE NOW \\ EXPERIENCE NEW CAMERA.}
[3 Like
$\square$ Comment
$\bowtie$ Share

Figure A1. Stimulus 1 (Sponsored Ad with emoji in the emoji condition).

\section{SNAPTECCHA SNAP TECH Inc.}

Experience the joy of TechCam's all-new digital camera. Moments with your family and friends will be instantly captured and saved in SNS and your cloud. And update your Youtube status everyday. Record and share your joyous moments with TechCam.
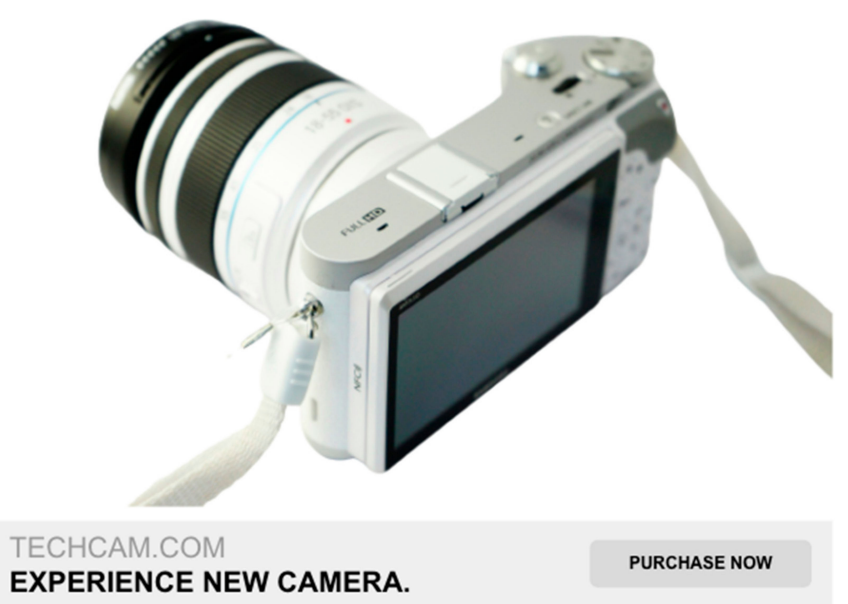
(1) Like
Comment
ळ) Share

Figure A2. Stimulus 2 (Sponsored Ad without emoji in the controlled condition). 


\section{References}

1. Fuller, D.A. Sustainable Marketing: Managerial-Ecological Issues; Sage Publications: New York, NY, USA, 1999.

2. Kim, C.; Jeon, H.G.; Lee, K.C. Discovering the Role of Emotional and Rational Appeals and Hidden Heterogeneity of Consumers in Advertising Copies for Sustainable Marketing. Sustainability 2020, 12, 5189. [CrossRef]

3. Rodríguez-Hidalgo, C.; Tan, E.S.; Verlegh, P.W. Expressing emotions in blogs: The role of textual paralinguistic cues in online venting and social sharing posts. Comput. Hum. Behav. 2017, 73, 638-649. [CrossRef]

4. Morris, J.D.; Choi, Y.; Ju, I. Are social marketing and advertising communications (SMACs) meaningful?: A survey of Facebook user emotional responses, source credibility, personal relevance, and perceived intrusiveness. J. Curr. Issues Res. Advert. 2016, 37, 165-182. [CrossRef]

5. Luangrath, A.W.; Peck, J.; Barger, V.A. Textual paralanguage and its implications for marketing communications. J. Consum. Psychol. 2017, 27, 98-107. [CrossRef]

6. Boerman, S.C.; Willemsen, L.M.; Van Der Aa, E.P. “This post is sponsored”: Effects of sponsorship disclosure on persuasion knowledge and electronic word of mouth in the context of Facebook. J. Interact. Mark. 2017, 38, 82-92. [CrossRef]

7. Derks, D.; Bos, A.E.; Von Grumbkow, J. Emoticons in computer-mediated communication: Social motives and social context. Cyberpsychol. Behav. 2008, 11, 99-101. [CrossRef] [PubMed]

8. Hsieh, W.-T.; Stu, J.; Chen, Y.-L.; Chou, S.-C.T. A collaborative desktop tagging system for group knowledge management based on concept space. Expert Syst. Appl. 2009, 36, 9513-9523. [CrossRef]

9. Young, A.L.; Quan-Haase, A. Privacy protection strategies on Facebook: The Internet privacy paradox revisited. Inf. Commun. Soc. 2013, 16, 479-500. [CrossRef]

10. Cain, R.M. Embedded advertising on television: Disclosure, deception, and free speech rights. J. Public Policy Mark. 2011, 30, 226-238. [CrossRef]

11. Li, H.; Edwards, S.M.; Lee, J.-H. Measuring the intrusiveness of advertisements: Scale development and validation. J. Advert. 2002, 31, 37-47. [CrossRef]

12. Van Kleef, G.A. How emotions regulate social life: The emotions as social information (EASI) model. Curr. Dir. Psychol. Sci. 2009, 18, 184-188. [CrossRef]

13. Walther, J.B.; D'addario, K.P. The impacts of emoticons on message interpretation in computer-mediated communication. Soc. Sci. Comput. Rev. 2001, 19, 324-347. [CrossRef]

14. Li, X.; Chan, K.W.; Kim, S. Service with emoticons: How customers interpret employee use of emoticons in online service encounters. J. Consum. Res. 2019, 45, 973-987. [CrossRef]

15. McShane, L.; Pancer, E.; Poole, M.; Deng, Q. Emoji, playfulness, and brand engagement on twitter. J. Interact. Mark. 2021, 53, 96-110. [CrossRef]

16. Hsieh, S.H.; Tseng, T.H. Playfulness in mobile instant messaging: Examining the influence of emoticons and text messaging on social interaction. Comput. Hum. Behav. 2017, 69, 405-414. [CrossRef]

17. Thompson, D.; Filik, R. Sarcasm in written communication: Emoticons are efficient markers of intention. J. Comput. Commun. 2016, 21, 105-120. [CrossRef]

18. Kaye, L.K.; Wall, H.J.; Malone, S.A. "Turn that frown upside-down": A contextual account of emoticon usage on different virtual platforms. Comput. Hum. Behav. 2016, 60, 463-467. [CrossRef]

19. Riordan, M.A. The communicative role of non-face emojis: Affect and disambiguation. Comput. Hum. Behav. 2017, 76, 75-86. [CrossRef]

20. Miller, H.; Thebault-Spieker, J.; Chang, S.; Johnson, I.; Terveen, L.; Hecht, B. “Blissfully Happy" or "Ready to Fight": Varying Interpretations of Emoji. In Proceedings of the International AAAI Conference on Web and Social Media, Cologne, Germany, 17-20 May 2016.

21. Wijeratne, S.; Balasuriya, L.; Sheth, A.; Doran, D. A semantics-based measure of emoji similarity. In Proceedings of the International Conference on Web Intelligence, Leipzig, Germany, 23-27 August 2017; pp. 646-653.

22. Danesi, M. The Semiotics of Emoji: The Rise of Visual Language in the Age of the Internet; Bloomsbury Publishing: London, UK, 2016.

23. Ge, J.; Gretzel, U. Emoji rhetoric: A social media influencer perspective. J. Mark. Manag. 2018, 34, 1272-1295. [CrossRef]

24. Das, G.; Wiener, H.J.; Kareklas, I. To emoji or not to emoji? Examining the influence of emoji on consumer reactions to advertising. J. Bus. Res. 2019, 96, 147-156. [CrossRef]

25. Njenga, K. Social media information security threats: Anthropomorphic emoji analysis on social engineering. In IT Convergence and Security 2017; Springer: Berlin/Heidelberg, Germany, 2018; pp. 185-192.

26. Rodrigues, D.; Lopes, D.; Prada, M.; Thompson, D.; Garrido, M.V. A frown emoji can be worth a thousand words: Perceptions of emoji use in text messages exchanged between romantic partners. Telemat. Inform. 2017, 34, 1532-1543. [CrossRef]

27. Yakın, V.; Eru, O. An application to determine the efficacy of emoji use on social marketing ads. Int. J. Soc. Sci. Educ. Res. 2017, 3, 230-240. [CrossRef]

28. Friestad, M.; Wright, P. The persuasion knowledge model: How people cope with persuasion attempts. J. Consum. Res. 1994, 21, 1-31. [CrossRef]

29. Boerman, S.C.; Van Reijmersdal, E.A.; Neijens, P.C. Using eye tracking to understand the effects of brand placement disclosure types in television programs. J. Advert. 2015, 44, 196-207. [CrossRef] 
30. Youn, S.; Kim, S. Newsfeed native advertising on Facebook: Young millennials' knowledge, pet peeves, reactance and ad avoidance. Int. J. Advert. 2019, 38, 651-683. [CrossRef]

31. Brehm, S.; Brehm, J. Psychological Reactance: A Theory of Freedom and Control; Academic Press: New York, NY, USA, 1981.

32. Van Kleef, G.A. The Interpersonal Dynamics of Emotion; Cambridge University Press: Cambridge, UK, 2016.

33. D'Astous, A.; Chartier, F. A study of factors affecting consumer evaluations and memory of product placements in movies. $J$. Curr. Issues Res. Advert. 2000, 22, 31-40. [CrossRef]

34. Provine, R.R.; Spencer, R.J.; Mandell, D.L. Emotional expression online: Emoticons punctuate website text messages. J. Lang. Soc. Psychol. 2007, 26, 299-307. [CrossRef]

35. White, T.B.; Zahay, D.L.; Thorbjørnsen, H.; Shavitt, S. Getting too personal: Reactance to highly personalized email solicitations. Mark. Lett. 2008, 19, 39-50. [CrossRef]

36. Lin, C.A.; Kim, T. Predicting user response to sponsored advertising on social media via the technology acceptance model. Comput. Hum. Behav. 2016, 64, 710-718. [CrossRef]

37. Edwards, S.M.; Li, H.; Lee, J.-H. Forced exposure and psychological reactance: Antecedents and consequences of the perceived intrusiveness of pop-up ads. J. Advert. 2002, 31, 83-95. [CrossRef]

38. Tran, T.P. Personalized ads on Facebook: An effective marketing tool for online marketers. J. Retail. Consum. Serv. 2017, 39, 230-242. [CrossRef]

39. Tsang, M.M.; Ho, S.-C.; Liang, T.-P. Consumer attitudes toward mobile advertising: An empirical study. Int. J. Electron. Commer. 2004, 8, 65-78. [CrossRef]

40. Morimoto, M.; Chang, S. Consumers' attitudes toward unsolicited commercial e-mail and postal direct mail marketing methods: Intrusiveness, perceived loss of control, and irritation. J. Interact. Advert. 2006, 7, 1-11. [CrossRef]

41. $\mathrm{Xu}, \mathrm{D} . J$. The influence of personalization in affecting consumer attitudes toward mobile advertising in China. J. Comput. Inf. Syst. 2006, 47, 9-19.

42. Youn, S.; Shin, W. Adolescents' responses to social media newsfeed advertising: The interplay of persuasion knowledge, benefit-risk assessment, and ad scepticism in explaining information disclosure. Int. J. Advert. 2020, 39, 213-231. [CrossRef]

43. Zhu, Y.-Q.; Chang, J.-H. The key role of relevance in personalized advertisement: Examining its impact on perceptions of privacy invasion, self-awareness, and continuous use intentions. Comput. Hum. Behav. 2016, 65, 442-447. [CrossRef]

44. Alalwan, A.A. Investigating the impact of social media advertising features on customer purchase intention. Int. J. Inf. Manag. 2018, 42, 65-77. [CrossRef]

45. Jeong, Y.; Kim, Y. Privacy concerns on social networking sites: Interplay among posting types, content, and audiences. Comput. Hum. Behav. 2017, 69, 302-310. [CrossRef]

46. Baek, T.H.; Morimoto, M. Stay away from me. J. Advert. 2012, 41, 59-76. [CrossRef]

47. Tam, K.Y.; Ho, S.Y. Web personalization as a persuasion strategy: An elaboration likelihood model perspective. Inf. Syst. Res. 2005, 16, 271-291. [CrossRef]

48. Das, G.; Mukherjee, A.; Smith, R.J. The perfect fit: The moderating role of selling cues on hedonic and utilitarian product types. J. Retail. 2018, 94, 203-216. [CrossRef]

49. Youn, S.; Kim, S. Understanding ad avoidance on Facebook: Antecedents and outcomes of psychological reactance. Comput. Hum. Behav. 2019, 98, 232-244. [CrossRef]

50. Hayes, A.F. Introduction to Mediation, Moderation, and Conditional Process Analysis: A Regression-Based Approach; Guilford Publications: New York, NY, USA, 2017.

51. Preacher, K.J.; Hayes, A.F. SPSS and SAS procedures for estimating indirect effects in simple mediation models. Behav. Res. Methods Instrum. Comput. 2004, 36, 717-731. [CrossRef] [PubMed]

52. Preacher, K.J.; Hayes, A.F. Asymptotic and resampling strategies for assessing and comparing indirect effects in multiple mediator models. Behav. Res. Methods 2008, 40, 879-891. [CrossRef] [PubMed]

53. Glikson, E.; Cheshin, A.; Kleef, G.A.V. The dark side of a smiley: Effects of smiling emoticons on virtual first impressions. Soc. Psychol. Personal. Sci. 2018, 9, 614-625. [CrossRef]

54. Franke, N.; Keinz, P.; Steger, C.J. Testing the value of customization: When do customers really prefer products tailored to their preferences? J. Mark. 2009, 73, 103-121. [CrossRef]

55. Goldfarb, A.; Tucker, C. Online display advertising: Targeting and obtrusiveness. Mark. Sci. 2011, 30, 389-404. [CrossRef] 